\title{
Endoscopic necrosectomy using endobronchial ultrasonography and transnasal gastroscopy via the percutaneous route
}

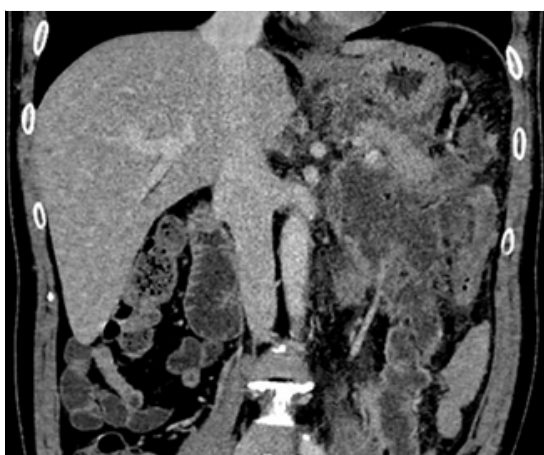

- Fig. 1 Coronal contrast-enhanced computed tomography (CE-CT) reveals extensive pancreatic necrosis and acute necrotic collections in the left subphrenic space extending deep into the pelvis. The necrotic collections are in contact with the small intestine.

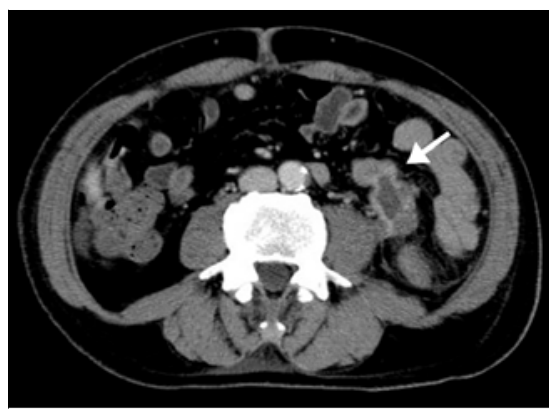

- Fig. 2 CE-CT reveals remarkable shrinkage of necrotic collections around the percutaneous tube. A remaining collection deep in the pelvis is in contact with the small intestine (arrow).

Severe acute pancreatitis often causes walled-off necrosis (WON). Despite recent reports of endoscopic transgastric necrosectomy using a lumen-apposing metal stent [1,2], treatment strategies for WON remain challenging.

A 53-year-old man with recurrence of ampullary adenoma underwent endoscopic treatment with argon plasma coagulation. Severe acute pancreatitis developed, which was managed conservatively. Four weeks later, the patient presented with fever, abdominal pain, and a

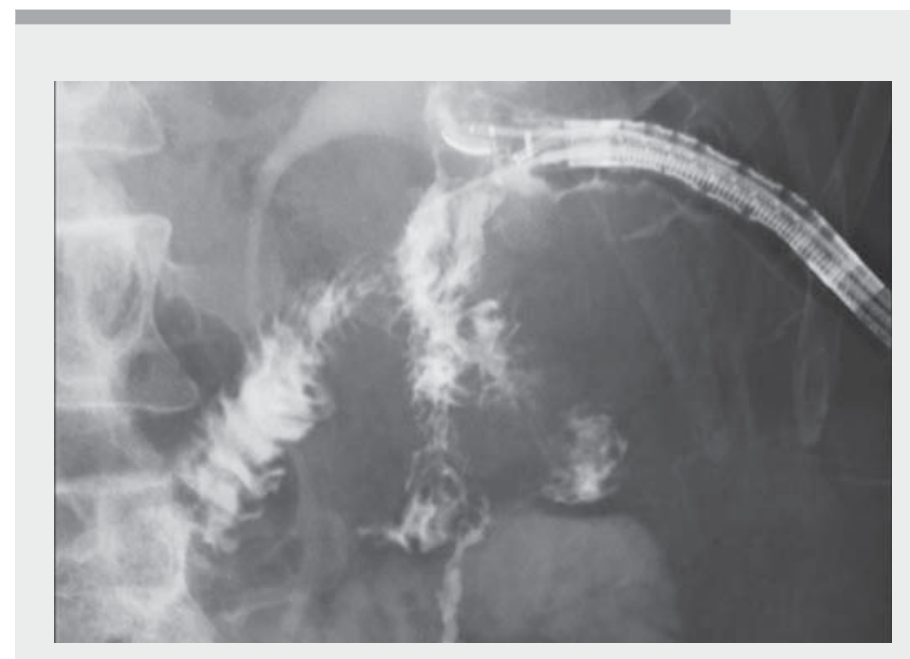

$\checkmark$ Video 1 Detection of a fistula between the left subphrenic space and the small intestine. A bronchial endoscope was inserted via the percutaneous route. Following puncture of the necrotic collection with a $21-G$ needle guided by endobronchial ultrasound, contrast medium was inserted through the needle and confirmed the presence of a fistula with the small intestine.
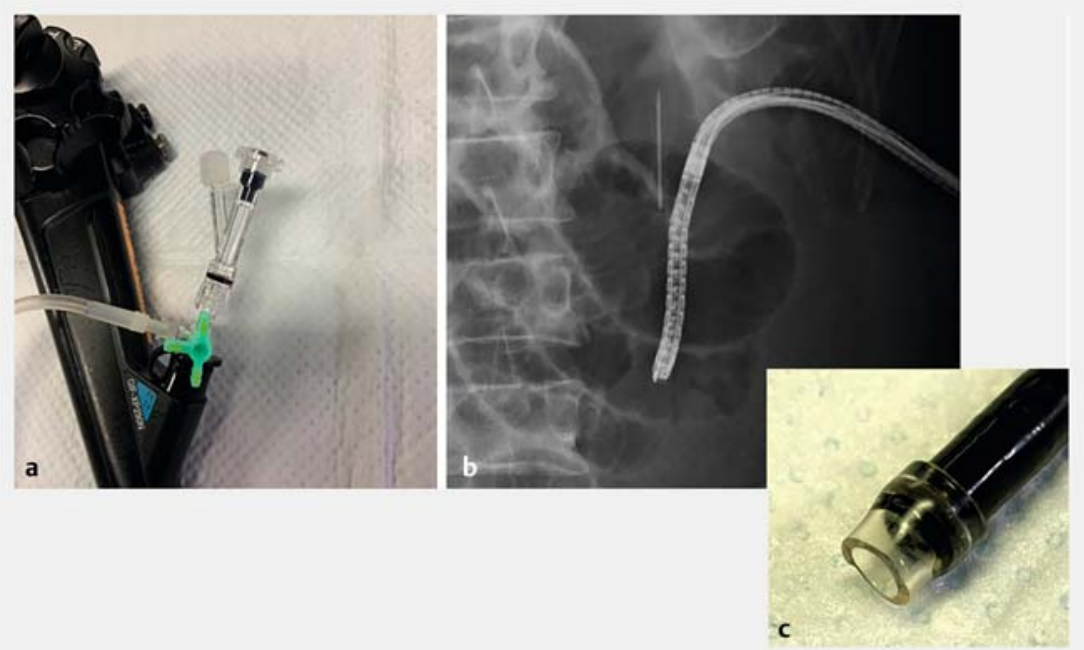

- Fig. 3 a Custom-made water supply system using a three-way stopcock and a pressureresistant connector (rotating hemostatic valve) for washing and using the transnasal gastroscope during necrosectomy. $\mathbf{b}$ Transnasal gastroscope inserted deep in the pelvic direction. $\mathbf{c}$ The addition of a cap made from tubing enabled scraping of necrotic tissue.

significant rise in C-reactive protein. Contrast-enhanced computed tomography (CE-CT) revealed extensive pancreatic necrosis and acute necrotic collections
( $\triangleright$ Fig. 1). Percutaneous drainage of the left subphrenic space was performed initially using a 12-Fr tube due to insufficient encapsulation. Then, we performed 
endoscopic necrosectomy four times using a gastroscope (GIF-Q260]; Olympus) via the percutaneous route. The patient's general condition improved, but a fistula with the small intestine was suspected. CE-CT revealed a significant reduction in the volume of necrotic collections and the presence of a collection deeper in the pelvis ( $>$ Fig. 2 ). We inferred that a fistula with the small intestine had formed in this area, but we could not detect it. First, we attempted access using endoscopic ultrasound (UCT260; Olympus), but we could not insert the scope owing to its large diameter. We then tried using endobronchial ultrasound (EBUS) (BF-UC290F; Olympus) ( Video 1). The collection was visualized using EBUS with Sonazoid (perflubutane; GE Healthcare) and was punctured with a 21-G needle (NA-201SX-4021; Olympus). Contrast imaging confirmed a fistula with the small intestine ( Video 1 ). We inserted a transnasal gastroscope (GIF-XP290N; Olympus) with a custom-made cap and water supply system and performed necrosectomy using a snare (SpyGlass Retrieval Snare; Boston Scientific) ( $\triangleright$ Fig. 3). A drainage tube was inserted near the fistula. After three additional necrosectomy procedures, the patient's condition improved and he was discharged.

EBUS and a transnasal gastroscope are very useful for drainage of necrotic collections when the route towards the pelvis is narrow with acute angles. The use of multiple devices was highly effective for treating this patient with severe WON.

Endoscopy_UCTN_Code_TTT_1AR_2AI

\section{Competing interests}

Competing interests

The authors declare that they have no conflict of interest.

The authors

Nozomi Okuno ${ }^{1}$, Kazuo Hara ${ }^{1}{ }^{\complement}$ Shin Haba ${ }^{\complement}$ Akira Miyano, Toshifumi Yanaidani, Daiki Fumihara, Masahiro Yoshida

Department of Gastroenterology, Aichi Cancer

Center Hospital, Nagoya, Aichi, Japan

Corresponding author

\section{Kazuo Hara, MD}

Department of Gastroenterology, Aichi Cancer Center Hospital, 1-1 Kanokoden, Chikusa-ku, Nagoya, Aichi 464-8681, Japan khara@aichi-cc.jp

\section{References}

[1] Chen YI, Yang J, Friedland S et al. Lumen apposing metal stents are superior to plastic stents in pancreatic walled-off necrosis: a large international multicenter study. Endosc Int Open 2019; 7: E347-E354
[2] Siddiqui AA, Kowalski TE, Loren DE et al. Fully covered self-expanding metal stents versus lumen-apposing fully covered selfexpanding metal stent versus plastic stents for endoscopic drainage of pancreatic walled-off necrosis: clinical outcomes and success. Gastrointest Endosc 2017; 85: 758765

\section{Bibliography}

Endoscopy 2022; 54: E83-E84

DOI 10.1055/a-1388-5811

ISSN 0013-726X

published online 15.3.2021

(C) 2021. Thieme. All rights reserved.

Georg Thieme Verlag KG, Rüdigerstraße 14, 70469 Stuttgart, Germany

\section{ENDOSCOPY E-VIDEOS}

https://eref.thieme.de/e-videos

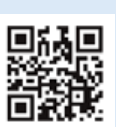

Endoscopy E-Videos is an open access online section, reporting on interesting cases and new techniques in gastroenterological endoscopy. All papers include a high quality video and all contributions are freely accessible online. Processing charges apply (currently EUR 375), discounts and wavers acc. to HINARI are available.

This section has its own submission website at https://mc.manuscriptcentral.com/e-videos 